\title{
Governança da água e inovação na política de recuperação de recursos hídricos na cidade de São Paulo
}

\author{
Water governance and innovation in the policy \\ of water resources recovery in the city of São Paulo
}

Pedro Roberto Jacobi

Ana Paula Fracalanza

Solange Silva-Sánchez

\section{Resumo}

A degradação ambiental de rios e córregos urbanos nas grandes cidades tem suscitado a formulação de diferentes políticas públicas. Este artigo analisa políticas públicas visando a recuperação ambiental de córregos urbanos, como novo paradigma na gestão dos recursos hídricos. 0 texto aborda o padrão de urbanização da cidade de São Paulo que resultou na degradação de seus recursos hídricos e o alcance das políticas públicas voltadas à sua recuperação. Em um contexto de córregos contaminados, várzeas ocupadas por favelas, ausência de rede coletora e de tratamento de esgotos, políticas de recuperação ambiental da rede hídrica podem transformar esses córregos em importantes prestadores de serviços ecossistêmicos. As políticas de recuperação de rios e córregos urbanos têm um potencial reconhecidamente inovador e podem contribuir para a construção de uma cidade mais sustentável.

Palavras-chave: município de São Paulo; governança da água; degradação ambiental; recuperação recursos hídricos; parques lineares.

\begin{abstract}
The degradation of urban rivers and creeks in large cities has stimulated the proposition of different public policies. This article analyzes public policies targeted at the environmental recovery of urban creeks as a new paradigm in the governance of water resources. The text approaches the urbanization pattern of the city of São Paulo, which has produced the degradation of its water resources, and the reach of public policies that aim at their recovery. In a context of contaminated creeks, floodplains occupied by squatter settlements, and lack of collection and treatment of sewage, policies for the environmental recovery of the water network can transform these creeks into important providers of ecosystemic services. Policies of recovery of urban rivers and creeks have a recognized innovative potential and can contribute to build a more sustainable city.
\end{abstract}

Keywords: municipality of São Paulo; water governance; environmental degradation; recovery of water resources; linear parks. 


\section{Introdução}

A cidade de São Paulo é o maior município da Região Metropolitana de São Paulo, com mais de onze milhões de habitantes. Sua estrutura hidrográfica é formada por 82 bacias contidas integralmente em seu território e outras 21, contidas apenas parcialmente no município. Os principais cursos d'água totalizam mais de cem afluências dos rios Tietê, Pinheiros, Tamanduateí, além das bacias que drenam as represas Guarapiranga e Billings, na região sul do município (São Paulo, 2012).

0 padrão de estruturação urbana que se estabeleceu no município provocou uma significativa degradação de seus recursos hídricos, com a ocupação intensiva e irregular de áreas de mananciais e fundos de vale. Além de ter resultado em uma elevada impermeabilização do solo urbano e na contaminação dos cursos d'água em razão da ausência de uma rede adequada de coleta e tratamento de esgotos, a ocupação dessas áreas ambientalmente frágeis colocou em situação de risco aqueles que ocupam as margens dos córregos da cidade (Rolnik e Nakano, 2000).

0 crescimento da cidade e os sucessivos planos e programas de intervenção urbana, como o "Plano de Melhoramentos do Rio Tietê", de 1922 e "Plano de Avenidas" de Prestes Maia, de 1930, resultaram em grandes modificações da rede hídrica original, com a canalização e retificação de cursos d'água e aterramento de várzeas. As várzeas dos rios Tietê, Pinheiros e Anhangabaú, que até a década de 1920 ainda se constituíam em grandes vazios urbanos, foram aterradas e urbanizadas. As obras de retificação do Rio Pinheiros previam o aproveitamento hidrelétrico, com a transposição de suas águas e construção das barragens dos rios Grande e Guarapiranga; a retificação do Tietê possibilitou a construção das vias marginais ligando o centro aos novos bairros que surgiam (São Paulo, 2004a). A paisagem natural, caracterizada pelos meandros dos rios, pelas extensas áreas de várzea foi sendo substituída por canais retilíneos, vias de fundo de vale, como é o caso da Avenida Nove de Julho. ${ }^{1}$ Modificações no ambiente, tais como a impermeabilização do solo, a alteração nos leitos e nas margens dos rios e a diminuição da cobertura vegetal nas cidades, são fatores que podem provocar alterações no ciclo da água. Uma situação exemplar desse fenômeno é a dimensão assumida pela transformação das enchentes em inundações, problema esse decorrente de alterações no espaço geográfico urbano.

A abordagem aqui desenvolvida tem como foco analítico o conceito de governança, que se baseia na premissa de ser resultado da ação de múltiplos atores, dentre os quais o Estado que, sem dúvida, é o mais importante. Configura-se assim o exercício deliberado e contínuo de desenvolvimento de práticas cujo foco analítico está na noção de poder social que media as relações entre estado, sociedade civil e agentes econômicos, e que podem ampliar os mecanismos de democracia participativa. 0 tema "governança" insere-se nas novas tendências da administração pública e de gestão de políticas públicas, principalmente quando se considera a possibilidade de incluir novos atores sociais no processo decisório no intuito de promover melhoria na gestão e avançar na democratização desses processos. Adota-se, 
portanto, uma visão que identifica todos os esforços relacionados com a construção social para articular teorias, agendas, sujeitos e potencialidades, construção de alianças e cooperação, além de acumular energia para romper com as abordagens verticais e estanques das atividades humanas e transcender aquelas que se baseiam na supremacia do mercado (Jacobi, 2012). Desse modo, configura-se um processo no qual se torna implícita a disseminação de alguns dos poderes centrais para instâncias do setor público, mais próximas da escala local decisória, e menos hierarquizadas, o que determina a inclusão de novos agentes, instituições e estruturas no processo decisório. Portanto, criam-se as condições para uma participação concertada entre vários representantes da sociedade civil na condução política e tomada decisória, em oposição à tradicional perspectiva top-down da administração centralizada.

A abordagem da governança ambiental tem uma história recente, ganha impulso a partir de meados da década de 1980 e refere-se a formas de governar os recursos naturais envolvendo diferentes atores - governo, empresariado e o espectro ampliado da sociedade civil. Abre-se um estimulante espaço para repensar as formas inovadoras de gestão, na medida em que fazem parte do sistema de governança: o elemento político, que consiste em balancear os vários interesses e realidades políticas; o fator credibilidade, instrumentos que apoiem as políticas, que façam com que a população identifique nas ações e decisões políticas a solução de seus problemas; e a dimensão ambiental.

0 processo de governança envolve múltiplas categorias de atores, instituições, inter-relações e temas, cada um dos quais suscetível a expressar arranjos específicos entre interesses em jogo e possibilidades de negociação, expressando aspectos de interesse de coletividades, com ênfase na prevalência do bem comum (Jacobi, 2012).

A literatura sobre o tema enfatiza a governança da água, como a realizada por meio da participação, envolvimento e negociação de multiatores (multi-stakeholders), da descentralização, transferindo poder para o governo local (empowerment), da unidade de gestão por bacia hidrográfica, por exemplo, e de mecanismos para resolução dos conflitos (Solanes e Jouralev, 2006; Castro, 2007).

Ao utilizar o conceito de governança, associam-se à implementação socialmente aceitável de políticas públicas, novos atores sociais na construção de agendas participativas, de modo que a gestão passa a considerar novas relações entre sociedade, estado, agentes econômicos, direito, instituições, políticas e ações governamentais.

No Brasil, as diferentes engenharias institucionais e transformações em curso nos organismos colegiados mostram que a implantação efetiva dos diversos instrumentos de participação pode mudar os padrões de governança, estabelecendo novas mediações entre estado e organizações da sociedade civil, baseadas no aprimoramento de suas relações democráticas. Poderão representar uma possibilidade efetiva de transformação da lógica de gestão da administração pública, abrindo um espaço de interlocução muito mais complexo, que amplia o grau de responsabilidade de segmentos que sempre tiveram participação assimétrica na gestão pública. 


\section{As águas na cidade de São Paulo: de 1890 a 2014}

Até o final do século XIX, São Paulo era um pacato vilarejo no planalto da Serra do Mar. Impulsionada pelo ciclo econômico do café, a cidade começa a se urbanizar, e diferentes atividades e serviços como bancos, estradas de ferro, eletricidade, comércio, indústria se desenvolvem (Araújo, 1992). A cidade, que tinha uma população de 50 mil habitantes em 1875, apresenta um crescimento populacional de $269 \%$ entre os anos de 1890 e 1900, e de $141 \%$ entre os anos de 1900 e 1920. Assim, começa-se a sentir os efeitos da ocupação humana, e as terras perdem sua vegetação, as águas se tornam vias transportadoras de esgotos, efluentes industriais e resíduos de todo tipo (Rutkowski et al., 2010). A demanda por água aumenta de forma continuada, e os aguadeiros são substituídos pelos chafarizes em praças públicas por onde as águas das nascentes jorram.

A capital da Província se moderniza, e em 1877, um grupo de empresários constituiu a Companhia Cantareira de Águas e Esgotos para distribuir água; entretanto, essa não consegue acompanhar o crescimento vertiginoso da cidade de São Paulo.

A indústria ocupava um papel de destaque nesse crescimento, principalmente em princípios do século XX e após a crise da economia cafeeira. Nesse sentido, passa-se a requerer ampliações significativas nos sistemas de água e esgotos, ensejando o surgimento dos primeiros serviços prestados diretamente pelo setor público.

É interessante observar que, já em 1883, apresentavam-se estudos sobre intervenções para o saneamento do rio Tietê, cujas águas já se encontravam poluídas (Nóbrega, 1981).

Em 1893, o Governo do Estado rescindiu o contrato de concessão que havia firmado com a Companhia Cantareira e criou a Repartição de Águas e Esgotos da Capital - RAE, subordinada à Secretaria de Agricultura, Comércio e Obras Públicas.

A construção da barragem em Santana de Parnaíba para a usina hidrelétrica Edgard de Souza, em 1900, e a grande estiagem de 1903 levam à construção da represa de Guarapiranga, em 1906, para regularizar a vazão do rio Tietê. A grande seca de 1910 leva a Repartição de Águas e Esgotos - RAE a reconhecer um déficit no abastecimento de água potável de 43\% das edificações abastecidas. Em 1917, é ampliada a capacidade de adução com captação de água no Rio Cotia e, em 1925, a RAE retira água no Rio Claro, na Serra do Mar. A seca de 1924 deixa um déficit no abastecimento de água potável da ordem de $56 \%$ na cidade de São Paulo. Em 1929, já se retirava água da represa do Guarapiranga, construída pela Light and Power, e nesse ano, é firmado o primeiro acordo entre o Governo do Estado e a Light, para regularizar o abastecimento de água da cidade de São Paulo (Rutkowski et al., 2010). Em 1928, a Light permite o uso de $4 \mathrm{~m}^{3} / \mathrm{s}$ das águas do reservatório Guarapiranga para 0 abastecimento público de água.

Em 1940, São Paulo editou a primeira legislação específica contra a poluição das águas e, em 1951, seu código de normas sanitárias. Em 1941, a cidade então com uma população superior a 1,3 milhão de habitantes, recebia água de cinco sistemas, num total de quase 470 milhões de litros diários. 
0 Conselho Estadual de Controle da Poluição das Águas classifica, em 1954, as águas da bacia do Guarapiranga como destinadas ao abastecimento público proibindo o lançamento de esgotos em sua bacia (Rutkowski et al., 2010). Problemas crescentes no abastecimento público de água provocam a ampliação da adução do sistema Guarapiranga e o aproveitamento de um braço do rio Grande, da represa Billings, para abastecer a região do $A B C$, enquanto o município de São Paulo proíbe o loteamento de terrenos que não tenham serviço público de água potável. Em 1947, é elaborado o 10 Plano Conjunto de Águas e Esgotos para a Capital e, em 1950, foi criado o Departamento de Obras Sanitárias. Três anos mais tarde, diante da expansão da metrópole paulistana, é extinta a RAE e criado o Departamento de Águas e Esgotos - DAE, responsável pela administração direta dos serviços de água e esgotos da capital e dos municípios vizinhos Osasco, São Caetano, Santo André e São Bernardo do Campo.

No final da década de 1950, o município de São Paulo torna obrigatória a canalização de córregos e o saneamento das bacias e vales para loteamentos. Entretanto, os instrumentos legais criados não têm o resultado esperado e a falta de um sistema de coleta de esgotos adequado reforça a multiplicação de doenças de veiculação hídrica, resultando em elevados índices de morbi-mortalidade infantil em São Paulo.

A expansão das periferias da cidade e as políticas viárias priorizam a retificação de canais e o aterramento de várzeas, ampliando a impermeabilização do solo e, consequentemente, aumentando o volume de inundações. Isso configura uma situação na qual a partir da segunda metade do século $\mathrm{XX}$, as necessidades da capital não podem mais ser tratadas dentro de seus limites municipais. Assim, em 1964, é contratado, pelo Departamento de Águas e Energia Elétrica do Estado de São Paulo DAEE, o primeiro plano diretor de usos múltiplos da bacia do Alto Tietê. No ano seguinte, define-se um cinturão verde para a cidade de São Paulo e o lançamento de resíduos industriais em cursos d'água paulistas é normatizado. Uma obra que mudaria a realidade hídrica da cidade de São Paulo e das áreas conurbadas inicia-se com a reversão da bacia do rio Piracicaba para o Sistema Cantareira em 1967.

Nessa época, o país promove forte centralização do processo decisório e cria, em âmbito nacional, órgãos encarregados de formular e gerir políticas urbanas, inclusive a de saneamento, implementando as diretrizes do setor de saneamento através da instituição do Sistema Financeiro de Saneamento - SFS, vinculado ao Banco Nacional de Habitação - BNH e do Plano Nacional de Saneamento - Planasa.

Implantado a partir de 1971, o Planasa, apoiou-se na concentração dos serviços de saneamento em empresas estaduais, em detrimento da gestão municipal, dando origem à criação das 27 companhias estaduais de saneamento existentes no País (Jacobi, 1989), e, no estado de São Paulo, essa política refletiu na criação de várias companhias e órgãos estaduais que centralizavam regionalmente os serviços e os investimentos.

Em 1968, a Companhia Metropolitana de Água de São Paulo - Comasp é criada para captar, tratar e vender água potável no atacado para a Grande São Paulo e recebe o Sistema Cantareira. Em 1969, é criada a Região Metropolitana de São Paulo - RMSP, e com 
a expansão demográfica ao longo dos anos 1970, sua população chega a 12.588 .725 habitantes, dos quais quase $70 \%$ residentes na cidade de São Paulo.

São criados, em 1970, a Companhia Metropolitana de Saneamento de São Paulo Sanesp para interceptar, tratar e proceder a disposição final dos esgotos da RMSP, e o Fomento Estadual de Saneamento Básico - Fesb para levantar fontes internas e externas de recursos necessários para a execução de programas de saneamento. Em 1973, o processo de centralização dos serviços de saneamento culmina com a criação da Companhia de Saneamento Básico do Estado de São Paulo - Sabesp, que entra em operação em 1974, incorporando as atividades da Comasp, Sanesp e DAE. São criados, no decorrer da década, diversos órgãos públicos e normas de abrangência metropolitana com o intuito de minimizar os problemas advindos da poluição dos corpos d'água paulistanos, destacando-se a legislação que instituiu as áreas de proteção aos mananciais e demais recursos hídricos de interesse da RMSP. ${ }^{2}$

A estratégia adotada pela Sabesp de agilidade no retorno dos investimentos priorizou ações para abastecimento de água potável em detrimento do tratamento dos esgotos sanitários, deteriorando mais rapidamente os caudais d'água das grandes cidades (Rutkowski et al., 2010). Atualmente, a Sabesp é responsável pelos serviços de água e esgotos da capital e de mais 365 municípios, e distribui água tratada para cerca de 22 milhões de pessoas.

Cabe considerar que a Região Metropolitana de São Paulo - RMSP é abastecida, em sua maior parte, por três grandes sistemas produtores de água: Sistema Cantareira, Sistema Guarapiranga-Billings e Sistema Alto Tietê.
A RMSP praticamente coincide com o território da Bacia Hidrográfica do Alto Tietê, que tem uma área de 5.900 km2 e é integrada por 35 municípios. Seus regimes hidráulico e hidrológico são extremamente complexos; em virtude das profundas alterações geradas pelas obras hidráulicas e pelo impacto de uma urbanização pouco regulada, que ocupa $37 \%$ do território.

Nessa bacia hidrográfica, o índice de coleta de esgotos, segundo os dados da Sabesp, é de $86 \%$ e o de tratamento de $65 \%$ (Sabesp, 2013). A Sabesp opera oito usinas de tratamento de esgoto na RMSP, o que representa $72 \%$ das águas residuais tratadas em todo 0 Estado de São Paulo; entretanto, há municípios que não são operados pela Sabesp, cujo sistema de coleta e tratamento é ainda muito insuficiente, o que prejudica a qualidade das águas que atravessam o município de São Paulo. Cabe ainda incluir no quadro de poluição das águas o fato de que, apesar de a RMSP ter níveis bastante adequados de coleta e descarte de resíduos sólidos domésticos, o montante não coletado ou descartado inadequadamente ainda é significativo, atingindo parcialmente os rios e córregos da região ${ }^{3}$ (Silva-Sanchez e Jacobi, 2012).

Avalia-se que $30 \%$ da carga poluidora total é lançada diretamente nos corpos d'água das bacias dos rios Tietê e Tamanduateí e do canal Pinheiros, todos classificados ${ }^{4}$ na classe 4, como águas que só podem ser destinadas à navegação e à harmonia paisagística. Já os mananciais do Sistema Cantareira e Alto Cotia são considerados como classe especial, ou seja, são águas destinadas ao abastecimento para consumo humano (com desinfecção), à preservação do equilíbrio natural das comunidades aquáticas e dos ambientes aquáticos em 
unidades de conservação de proteção integral (Rutkowski et al., 2010).

Do ponto de vista ambiental, a situação dos cursos d'água é considerada crítica, resultado de um conjunto de fatores que envolvem desde o parcelamento indiscriminado do solo nas periferias urbanas, a precariedade dos serviços prestados e até a omissão do poder público ao longo de décadas, seja em razão da ausência de planos eficazes, seja em decorrência de uma ação fiscalizadora quase sempre inadequada e impotente. A reversão desse quadro de degradação urbano-ambiental é bastante complexa e demanda o fortalecimento de ações relacionadas à construção social para articular teorias, agendas, sujeitos e potencialidades em torno de alianças e cooperação.

Diante desse quadro de degradação, uma mudança importante na gestão das águas no Estado de São Paulo ocorre em 1991, quando foi promulgada a Lei Paulista de Recursos Hídricos (Lei n. 7.663), depois de alguns anos de debate. Ela trazia uma proposta bastante inovadora, priorizando o uso da água para o abastecimento público, e tendo como princípios uma gestão descentralizada, participativa e integrada desses recursos. Essa lei criou ainda o Sistema Integrado de Gerenciamento dos Recursos Hídricos de São Paulo e implementou os Comitês de Bacias Hidrográficas - CBH como instâncias regionais de gestão.

0 primeiro $\mathrm{CBH}$ criado a partir dessa Lei foi o Comitê das Bacias Hidrográficas dos rios Piracicaba, Capivari e Jundiaí, em 1993, que vem sendo considerado como modelo organizacional para os comitês que surgiram depois. 0 processo de constituição do CBH-PCJ foi gradual e bastante negociado, devido à sua estrutura tripartite e pioneira, e também por implicar uma alteração das relações de poder existentes e das formas de resolução dos problemas hídricos da região.

Deve-se ressaltar que a criação do comitê foi resultado da mobilização regional pela falta d'água eminente devido à reversão das águas da Bacia do rio Piracicaba e afluentes para o Sistema Cantareira e ao volume de esgotos lançado, poluindo grande parte das águas desses rios. Esse processo inicia-se no final da década de 1960, quando a degradação dos recursos hídricos nas bacias PCJ gerou uma reação da população, impulsionada pela mortandade de peixes na região, causada pelo lançamento de vinhoto ou restilo nos rios e, mais tarde, de esgoto industrial e doméstico. Essa mobilização intensificou-se na década de 1970 com a intensa poluição dos rios, em virtude do crescimento demográfico e industrial ocorrido nessas bacias e com a reversão das águas através do Sistema Cantareira. As campanhas de mobilização foram fundamentais para a criação do Consórcio Intermunicipal das Bacias dos rios Piracicaba e Capivari em 1989, no qual se associaram onze municípios, por intermédio de seus prefeitos. A ideia principal que sustentou a fundação do Consórcio foi a de constituir uma organização que pudesse complementar a atuação das entidades tradicionalmente responsáveis pela execução de políticas públicas de saneamento e preservação do meio ambiente.

Após a criação do Comitês das Bacias Hidrográficas dos rios Piracicaba, Capivari e Jundiaí os Comitês de Bacia do Alto Tietê e da Baixada Santista foram instalados em 1994 e 1995, respectivamente. Os Planos Zero dos três comitês tiveram como prioridade o aumento da disponibilidade hídrica e, consequentemente, 0 tratamento de esgotos. 0 uso racional da água 
é um valor, mas ainda não um objetivo prioritário, já que o futuro imediato não prioriza novas maneiras de utilizar e consumir esse bem natural, recurso fundamental para todas as atividades urbanas, que minimize seu uso e evite seu desperdício (Rutkowski e De Oliveira, 1999).

No caso específico de áreas de proteção aos mananciais, que correspondem a cerca de $36 \%$ do território do município de São Paulo, a legislação de proteção ambiental, datada de 1976, impôs intensas restrições ao uso e ocupação do solo, provocando uma desvalorização no preço da terra que acabou por induzir uma ocupação desordenada da região, sobretudo no entorno das represas Billings e Guarapiranga. Falhas muito significativas na fiscalização, assim como a ausência de incentivo para os proprietários das terras, resultaram em intenso desmatamento de 1986 a 2000, quando a vegetação foi substituída por ocupação urbana ao longo de diversos cursos d'água dentro da microbacia do córrego Cabuçu de Baixo (Rares e Brandimarte, 2014).

Em 1997, foi aprovada uma nova legislação estadual ${ }^{5}$ para proteção aos mananciais, que busca compatibilizar as ações de proteção e preservação dos mananciais com a proteção ambiental, o uso e a ocupação do solo e o desenvolvimento socioeconômico das áreas protegidas, pelo estabelecimento de diretrizes gerais para as áreas de proteção e recuperação que devem ser regulamentadas em todas as áreas de mananciais. Assim, nos últimos anos essas áreas têm sido protegidas dentro do que se define como áreas do município de São Paulo que se localiza na face sul do Parque da Serra da Cantareira e no extremo sul do município.

Diante do exposto, considera-se que a possibilidade de superar o padrão urbanístico prevalecente e minimizar o quadro de degradação dos córregos urbanos, estabelecendo uma nova e eficiente gestão dos recursos hídricos, sob o paradigma da governança ambiental, pressupõe que se considerem os rios como espaços nos quais qualquer intervenção visando sua recuperação deve ser multiobjetiva, congregando objetivos de desenvolvimento econômico, de proteção ambiental, de promoção cultural e de construção de uma rede social dos atores envolvidos. Como prestadores de serviços ecossistêmicos, as intervenções em rios e córregos urbanos devem considerar a inter-relação dos aspectos físicos, bióticos e humanos. A sinergia das ações e da gestão das instituições públicas constitui outro princípio fundamental sob esse novo paradigma. Esses princípios têm como pressuposto que rios e córregos urbanos são elementos centrais para garantir a sustentabilidade das cidades (Silva-Sanchez e Jacobi, 2012).

\section{0 município de São Paulo: dinâmica de ocupação do solo e degradação das fontes hídricas}

Em 2014, o município de São Paulo conta com uma população de11.453.996 de habitantes, ${ }^{6}$ distribuída em uma área de $1.521 \mathrm{~km}^{2}$, que deverá ultrapassar doze milhões de habitantes em 2025. São Paulo caracteriza-se como o principal polo industrial do Brasil, com um Produto Interno Bruto de US\$210 milhões em 2011.7 0 orçamento do município em 2014 foi de US\$ 22 bilhões. $^{8}$ 
0 processo de urbanização, intensificado, sobretudo, a partir da primeira metade do século XX, expandiu-se rumo às áreas periféricas da cidade, carentes de infraestrutura e serviços básicos, com características naturais desfavoráveis à ocupação, como solos frágeis, áreas mais suscetíveis à erosão e acentuada declividade.

0 padrão de urbanização periférico criou uma cidade dividida. As favelas e os assentamentos precários foram se consolidando em áreas que não interessavam ao mercado imobiliário formal, sobretudo áreas com sérias restrições ambientais ou que não eram passíveis de urbanização, pois se localizavam em terrenos frágeis, encostas íngremes, várzeas inundáveis, margens de córregos ou áreas de mananciais.

Esse padrão de estruturação urbana que se estabeleceu ao longo dos anos resultou na total degradação dos recursos hídricos. A situação de degradação atinge desde grandes rios, como o Tietê e Pinheiros, como os pequenos córregos que formam a rede hidrográfica "capilar" do município. (Silva-Sánchez e Jacobi, 2012). Ressalte-se que os principais cursos d'água da cidade totalizam mais de cem afluências dos rios Tietê, Pinheiros, Tamanduateí, Juqueri e Capivari (São Paulo, 2014).

A ocupação irregular de áreas de preservação ambiental ocasiona a constituição de áreas de risco, erosão das margens dos rios e córregos e no assoreamento dos cursos d'água, perda das matas ciliares, alterações na topografia e impermeabilidade do solo, o que resulta em riscos socioambientais para a população que vive nessas áreas, assim como são acentuados os problemas de inundação na cidade. A produção de solo urbano, ao promover a impermeabilização do solo, canalização e retificação de cursos d'água, reduz a capacidade de infiltração e retenção das águas de chuva. Considera-se que $37 \%$ das terras da Bacia $\mathrm{Hi}-$ drográfica do Alto Tietê estão impermeabilizadas. Entretanto, o alargamento e aprofundamento da calha do rio Tietê, como medidas de minimização das enchentes e revitalização que ocorrem na cidade, apenas começaram no início dos anos 1990, embora a dragagem ocorresse desde os anos 1970, promovidas pelo Departamento de Águas e Energia Elétrica - DAEE dentro da área metropolitana.

Além do problema da impermeabilização do solo, a poluição das águas é outro aspecto a ser enfrentado. Nas últimas décadas, o setor industrial tem avançado quanto ao cumprimento da legislação, no que se refere ao tratamento de efluentes, e isso tem reduzido a poluição de origem industrial nas águas na Bacia Hidrográfica do Alto Tietê. Por outro lado, os esgotos domésticos continuam sendo os maiores responsáveis pela poluição da água da Região Metropolitana de São Paulo. 0 maior desafio é conectar mais de 200 mil domicílios à rede de esgoto, o que significa atender mais de 1,5 miIhão de pessoas, além de elevar os índices de tratamento de esgoto.

Um dos principais sistemas de abastecimento da região metropolitana, o sistema Guarapiranga, responsável por fornecer água para cerca de $30 \%$ da população paulistana, encontra-se em situação crítica (São Paulo, 2004a; Beyruth, 2006; Baltrusis e Ancona, 2006; Martins, 2011). Assim como no caso do Reservatório do Guarapiranga, o passivo ambiental representado pela contaminação das águas dos principais reservatórios da cidade de São Paulo, resultado do insuficiente investimento nos sistemas de coleta, transporte e tratamento de esgoto, somente na década de 1990 começou 
a ser enfrentado por políticas públicas efetivas, em parte financiadas por recursos do Banco Mundial.

Esse é o caso do Projeto Tietê, um dos maiores programas de saneamento ambiental do Brasil. Iniciado em 1992, já está na sua terceira fase, tendo consumido mais de US\$ 2 biIhões, contado com recursos do Banco Mundial, do BID e de Bancos Japoneses. Na RMSP, o Projeto Tietê ampliou a rede coletora de esgotos de $70 \%$ para $84 \%$ e o índice de tratamento de $24 \%$ para $70 \%{ }^{9}$

Outro aspecto a considerar está associado com as tecnologias de construção da cidade, que priorizaram o tamponamento dos córregos e a construção de avenidas de fundo de vale como soluções (Bartalini, 2006; Rolnik e Klink, 2011). Ao longo de décadas predominou uma abordagem setorizada, com predomínio de projetos localizados que não levaram em consideração as características ambientais da bacia hidrográfica, privilegiando obras de canalização, que, além de representarem altos custos para o poder público, aumentam mais do que reduzem os problemas que pretendem resolver (Tucci, 2008).

Desse modo, ademais da contaminação dos cursos d'água, por décadas predominaram na cidade de São Paulo políticas públicas que confinaram os rios e córregos em canais retilíneos, enterrando-os e para abrir ao longo deles grandes eixos viários. Mesmo quando as questões ambientais já tinham passado a integrar a agenda política internacional, a municipalidade adotava soluções pautadas na canalização de córregos ou em alternativas "tecnocráticas", como a construção de reservatórios para controle de cheias, popularmente conhecidos como piscinões (Silva-Sánchez e
Jacobi, 2012), que funcionam para detenção ou retenção de água e têm a finalidade de reduzir o efeito das enchentes. Nos anos 1980 e 1990, inúmeros córregos na cidade de São Paulo foram canalizados para a construção de avenidas de fundo de vale, implicando o reassentamento de milhares de famílias (Brocaneli e Stuerner, 2008).

Nessa perspectiva foi criado, em 1998, 0 Plano Diretor de Macrodrenagem da Bacia Hidrográfica do Alto Tietê, objetivando combater as enchentes da RMSP por meio da construção de piscinões, rebaixamento da calha do rio Tietê, canalização de afluentes e construção de barragens. Os reservatórios de controle de cheias, os piscinões, alteram a forma de projetar o manejo das águas pluviais, buscando retardar o escoamento das águas durante os episódios de chuvas intensas (Rutkowski et al., 2010).

Muitos córregos que não se tornaram avenidas tiveram suas margens ocupadas por favelas, configurando áreas de risco. Estudos indicam que os domicílios localizados próximos a cursos d'água em geral são residências de famílias mais pobres e com piores níveis de renda e educação, configurando uma situação de "alta vulnerabilidade socioambiental" (Alves e Torres, 2006).

Diversas pesquisas desenvolvidas com moradores residentes próximos a córregos e rios urbanos na cidade de São Paulo indicaram que, de modo geral, não se atribui a esses corpos hídricos atributos positivos; muitos moradores ainda consideram que a melhor intervenção seria sua canalização e resistem em conferir credibilidade a uma nova forma de tratar a água urbana (Bartalini, 2006; Jacobi e Giorgetti, 2009; Silva-Sánchez, 2011). 
Entretanto, a proteção e recuperação dos córregos e rios urbanos constituem preocupação de uma parcela significativa da população paulistana, conforme pesquisa de opinião pública conduzida pela prefeitura de São Paulo em 2011. ${ }^{10}$

A possibilidade de superar o padrão urbanístico prevalecente e o quadro de degradação da água urbana, estabelecendo uma efetiva gestão dos recursos hídricos na cidade, associa-se à requalificação de seus rios e córregos. No âmbito nacional, o Plano Nacional de Recursos Hídricos reconhece a importância da efetiva inserção dos municípios na gestão dos recursos hídricos, "particularmente em razão dos impactos sobre as águas, derivados do uso e ocupação do solo" (MMA, 2006).

No caso do município de São Paulo, em 2002, o Plano Diretor Estratégico criou o Programa de Recuperação Ambiental de Cursos d'Água e Fundos de Vale, estabelecendo uma série de ações e intervenções urbanas com o objetivo de recuperar os córregos da cidade. 0 sistema de rios e córregos foi concebido no plano diretor como um dos elementos de estruturação do território, para o qual se estabeleceram medidas de recuperação urbano-ambiental (São Paulo, 2004b; Travassos, 2010). Esse programa foi mantido no novo Plano Diretor Estratégico, ${ }^{11}$ aprovado em julho de 2014, sendo os parques lineares um de seus componentes principais. De acordo como o novo Plano Diretor, os projetos dos parques lineares deverão ser elaborados de forma participativa, e sua plena implantação pressupõe a articulação de ações de saneamento, drenagem, sistema de mobilidade, urbanização de interesse social, conservação ambiental e paisagismo. 0 Plano Diretor, que estabelece diretrizes para um horizonte de doze anos, prevê a criação de 43 novos parques lineares na cidade.

Convém mencionar que o novo Plano Diretor Estratégico ${ }^{12}$ recriou a zona rural no município de São Paulo em setores onde se pretende conter o crescimento urbano e garantir a preservação dos ecossistemas naturais, notadamente a área de mananciais, na porção sul do município e a borda da serra da Cantareira, no extremo norte da cidade. Para atingir esse objetivo, o novo Plano Diretor regulamentou, entre outros instrumentos, 0 pagamento por serviços ambientais, que visa remunerar os proprietários de terras localizadas nas áreas classificadas como de proteção ambiental que, entre outras ações, recuperem nascentes, matas ciliares e demais áreas de preservação permanente.

A recuperação da rede hídrica municipal também envolve uma ação da Sabesp em parceria com a Prefeitura de São Paulo, para implementação do Programa Córrego Limpo. Enquanto a Sabesp executa obras para ampliar as redes existentes, eliminar os lançamentos clandestinos de esgotos nos córregos e galerias de águas pluviais e também melhorar os sistemas de envio de esgotos às estações de tratamento, aumentando o número de residências conectadas às redes da Sabesp com a implantação de coletores-tronco, a Prefeitura executa a manutenção das margens e dos leitos dos córregos, reassenta as famílias residentes nos fundos de vale que vivem em situação de risco.

A parceria prevê uma ação conjunta e articulada de despoluição dos cursos d'água e implantação de parques lineares, reconhecendo a importância da intervenção na escala dos pequenos córregos e microbacias da cidade para garantir o sucesso de outros programas de 
escala metropolitana como o Projeto Tietê e o programa de proteção aos mananciais. ${ }^{13}$

0 Programa Córrego Limpo vem sendo executado há oito anos e está na sua quarta fase, que se encerra em dezembro de 2014. Até o momento, 146 córregos foram despoluídos, de um universo de cerca de 1.700 córregos (Sabesp, 2012). A Sabesp monitora mensalmente os córregos, que passam a ser considerados "despoluídos" quando atingem um valor igual ou menor que $30 \mathrm{DBO} .{ }^{14} \mathrm{~A}$ implementação do Programa se dá por sub-bacias, sendo realizada a despoluição de um córrego principal e depois de seus afluentes (por exemplo, o córrego Ipiranga, na região sul da cidade, com mais de dez quilômetros de extensão e cerca de 40 afluentes). 0 sucesso na despoluição dessas sub-bacias terá um efeito considerável na despoluição dos grandes rios como o Tietê e Pinheiros.

Em 2010, estado e município de São Paulo celebraram um convênio acordando implementar ações de forma associada com o objetivo de viabilizar a universalização do oferecimento universal e adequado dos serviços de abastecimento de água e esgotamento sanitário na capital com prazo de trinta anos. A Sabesp ficou com a exclusividade de prestação desses serviços e a Agência Reguladora de Saneamento e Energia do Estado de São Paulo - Arsesp ficou responsável pelas funções de regulação, inclusive tarifária, controle e fiscalização dos serviços. Note-se que embora seja uma concessão do município, a revisão tarifária da Sabesp é de competência Arsesp.

Como empresa que explora os serviços de abastecimento de água e esgotamento sanitário do município, a Sabesp está obrigada por lei ${ }^{15}$ a investir $7,5 \%$ sobre a receita bruta obtida a partir da exploração dos referidos serviços, no Fundo Municipal de Saneamento Ambiental e Infraestrutura e outros 13\% em ações de saneamento básico e ambiental de interesse do município. ${ }^{16}$

O Fundo Municipal de Saneamento Ambiental e Infraestrutura tem por função a destinação de recursos para diversas atividades relacionadas ao saneamento tais como intervenções em áreas ocupadas por população de baixa renda, visando a regularização urbanística e fundiária, limpeza, despoluição e canalização de córregos, melhoria do sistema viário, provisão habitacional para atendimento de famílias em assentamentos precários e implantação de parques visando a proteção das condições naturais e de produção de água no Município. Até 2014, a Sabesp investiu R\$100.409.000,48 (coletores tronco) e a prefeitura, $R \$ 340.471 .00,69$ (incluindo remoção de favelas em córregos e construção de unidades habitacionais). ${ }^{17}$

Paralelamente às ações de intervenção na rede de esgotamento, a parceria entre Sabesp e Prefeitura de São Paulo prevê o desenvolvimento de um programa de educação ambiental junto às comunidades residentes no entorno dos córregos, com foco na redução da poluição difusa, associada ao abandono de lixo nas margens dos cursos d'água e na correta utilização da rede de esgotos, de modo a evitar rompimentos, entupimentos ou mesmo lançamento irregular de águas pluviais na rede de esgotos.

Embora o Programa Córrego Limpo tenha sido desenhado de modo a articular ações de saneamento, urbanização e requalificação dos córregos urbanos, com a implantação de parques lineares pelo poder público municipal, essa articulação não ocorreu de forma efetiva. 
Ademais, um dos principais entraves para a efetiva implementação do Programa Córrego Limpo é a dificuldade de fazer convergir diferentes políticas setoriais, em particular os programas habitacionais e os parques lineares.

Com efeito, grande parte dos córregos ao longo dos quais foram implantados parques lineares não foi contemplada pelo programa "Córrego Limpo". Até 2012, dos dezessete parques lineares implantados na cidade de São Paulo, apenas quatro tiveram seus córregos despoluídos pelo programa dentro da abrangência do município de São Paulo (Silva-Sánchez e Jacobi, 2014).

Essa dificuldade em coordenar as intervenções, aliada às dificuldades operacionais, como falta de espaço físico para a passagem dos coletores-tronco em razão das ocupações irregulares às margens dos cursos d'água ou mesmo a falta de adesão da população ao programa, já que a conexão à rede coletora implica um aumento no valor da conta a ser paga, explicam em grande medida o retorno a uma situação de degradação e contaminação dos córregos que foram contemplados pelo programa (O Estado de S.Paulo, 17/9/2012). ${ }^{18}$

A efetiva implantação de parques lineares pode contribuir para reverter essa situação, pois representa uma verdadeira transformação da paisagem urbana, ao promover a requalificação de espaços públicos, valorizando e integrando novamente os córregos à cidade, à paisagem urbana. As ações empreendidas pelo poder público municipal no âmbito do programa de recuperação de fundos de vale (Travassos, 2010), em particular com a implantação de parques lineares, em que pese uma série de problemas ainda não resolvidos, já se mostrou positiva e goza de legitimação social. 0 desafio é superar a forma fragmentada que historicamente caracteriza as ações do poder público, estabelecendo intervenções convergentes e uma gestão integrada das políticas públicas.

\section{Inovação na política de recuperação de recursos hídricos na cidade de São Paulo}

A temática da reabilitação ou recuperação dos córregos e rios urbanos integrou-se à pauta das políticas e do debate públicos contemporâneos de uma maneira que já não se restringe ao campo específico da engenharia civil, hidráulica ou de saneamento básico. Com efeito, a abordagem pressupõe uma visão complexa, multidimensional e multidisciplinar, que considere os rios como sistemas socioambientais prestadores de serviços ecossistêmicos, fonte de abastecimento, objeto de recuperação paisagística e elemento da memória coletiva e elemento central para garantir a sustentabilidade das cidades (Rodrigues, 2009; Reynoso, 2010; Silva-Sánchez e Jacobi, 2012; Travassos, 2010).

A reversão desse quadro é bastante complexa e depende da formulação e implementação de políticas públicas que articulem a gestão da água à gestão ambiental e de uso e ocupação do solo, integrando políticas setoriais.

A requalificação de rios urbanos apresenta uma nova abordagem na qual as iniciativas se propõem mais abrangentes do que as ações de saneamento que marcaram a recuperação de grandes rios (Saenz, 2010). Para além do objetivo exclusivo de melhorar a qualidade da 
água, há uma preocupação de reinserir rios e córregos na paisagem urbana, recuperar a memória sobre esses corpos hídricos, conectar espaços públicos, valorizar os serviços ambientais prestados à cidade pelos rios, sem desconsiderar a promoção da participação pública (Silva-Sánchez e Jacobi, 2012).

Na cidade de São Paulo, a implementação de uma política de recuperação de córregos e fundos de vale tem colocado desafios de diversas ordens ao poder público municipal. Além de superar os inúmeros constrangimentos burocráticos particulares a cada órgão, de modo que a necessária sinergia das ações públicas ocorra tanto internamente às instituições como entre diferentes esferas de governo, o poder público municipal precisa contemplar a diversidade de interesses e perspectivas no desenvolvimento e implementação dos projetos, promovendo o debate público e a participação social (Silva-Sánchez e Jacobi, 2012).

Em pouco mais de uma década após a criação do programa municipal de recuperação de córregos e fundos de vale, 17 parques lineares foram concluídos na cidade de São Paulo, uma parcela ínfima considerando que o Plano Diretor de 2002 previa mais de 30 parques lineares a serem criados. Ademais, vários parques lineares foram implantados de forma parcial, outros apresentam sérios problemas de conservação ou não foram desenvolvidos de modo a integrar políticas setoriais complementares. Da mesma forma, os processos de participação pública, quando existem, variam em cada caso, já que não há um desenho institucional de participação predefinido.

0 parque linear, como intervenção urbano-ambiental, se adequadamente implementado, pode significar uma verdadeira transformação da paisagem urbana, promovendo a requalificação de espaços públicos, a recuperação da qualidade da água e integrando novamente os córregos à cidade como sistemas socioambientais prestadores de importantes serviços ecossistêmicos (Silva-Sánchez e Jacobi, 2012).

Como elemento de qualificação da paisagem urbana, o parque linear inter-relaciona aspectos de drenagem, infraestrutura urbana e áreas verdes, podendo desempenhar funções ecológicas, estéticas, recreacionais, educacionais e de sociabilidade. 0 parque linear é caracterizado por múltiplas funções, como a manutenção da qualidade ambiental dos espaços urbanos, ampliação das áreas permeáveis e de cobertura vegetal, regulação de enchentes, manutenção da qualidade dos solos, conservação da água (superficial e subterrânea), regulação microclimática, ampliação das áreas de lazer, promovendo bem-estar e convívio social, além de constituir um espaço privilegiado para práticas de educação ambiental. 0 parque linear representa um conceito de uso multifuncional de um córrego e de suas margens que privilegia a conservação dos recursos hídricos e a qualidade ambiental, em contraste com as formas estabelecidas de uso, nas quais os córregos são tratados seja como obstáculos ao desenvolvimento, seja como meio de diluição e afastamento de esgotos, e suas margens como áreas aproveitáveis para implantação de vias de tráfego.

Dada a complexidade dos problemas a serem considerados nos projetos de parques lineares, uma ação intersetorial é condição para que sua implementação ocorra sob uma sinergia de ações e gestão das instituições públicas (Saenz, 2010). No âmbito do município, essas 
ações são empreendidas por diferentes secretarias, departamentos, e mesmo outros níveis de governo, e quase sempre implicam remoção de favelas em área de risco, construção de moradias populares, obras de controle de erosão, a própria despoluição do corpo hídrico e instalação de coletores-tronco de esgoto, desenvolvimento do projeto paisagístico associado a áreas de lazer, além de trabalhos de educação ambiental, configurando um alto nível de complexidade institucional.

A estrutura organizacional da administração municipal, ainda fortemente centralizada, seja em relação à tomada de decisão seja em relação aos recursos financeiros, agrava ainda mais o problema. As subprefeituras, representação política local da administração municipal, não dispõem de estrutura e autonomia suficientes para cumprir seu papel efetivo de agente indutor do desenvolvimento local, conforme preconiza a legislação. Uma descentralização mais efetiva da administração pública, em uma cidade com as dimensões de São Paulo, poderia conferir mais agilidade à implantação de certas intervenções urbanísticas como é o caso dos parques lineares (Silva-Sánchez e Manetti, 2007).

Além disso, a multiplicidade de atores envolvidos no processo de implantação de parques lineares constitui um desafio ao poder público, atores esses com culturas e procedimentos diferentes, como é o caso de organizações da sociedade civil, da população moradora no entorno, até representantes do mercado imobiliário. As interações sociais e os diferentes papéis exercidos por esses atores tornam esse processo um espaço de negociação política, que pode envolver um amplo aprendizado social (Mostert et al., 2007; Petts, 2006; Jacobi, 2011).
Não obstante os problemas verificados, que poderiam até anular, pelo menos em parte, os benefícios urbano-ambientais esperados com a criação dos parques lineares, a receptividade e a apropriação desses espaços recuperá-los pela população, têm sido bastante positivas (Silva-Sánchez e Jacobi, 2014). A percepção da população que mora ou trabalha nos locais onde os parques lineares foram implantados foi positivamente modificada em relação ao córrego e às áreas públicas associadas, ainda que se reconheça a permanência de vários problemas preexistentes e a incompletude das intervenções, no sentido de que questões fundamentais, entre as quais a despoluição dos córregos, não foram resolvidos. Ao parque linear foi associada a possibilidade de que seja promovida maior sociabilidade na vizinhança.

Em áreas carentes, marcadas pelo acúmulo de deficiências de várias ordens, como a precariedade de acesso a bens e serviços, a segurança e a um padrão de habitação satisfatório, os efeitos urbanísticos e ambientais decorrentes da criação dos parques lineares foram ainda mais relevantes (Silva-Sánchez e Jacobi, 2014).

0 novo Plano Diretor do município de São Paulo ${ }^{19}$ prevê que os projetos dos parques lineares deverão ser elaborados de forma participativa, e sua plena implantação pressupõe a articulação de ações de saneamento, drenagem, sistema de mobilidade, urbanização de interesse social, conservação ambiental e paisagismo.

A recuperação de córregos e rios urbanos na cidade de São Paulo ainda tem baixa efetividade, que decorre da baixa capacidade do poder público para constituir mecanismos eficazes de planejamento e gestão, notadamente 
para elaboração de políticas de longo prazo, como são as políticas ambientais. Ainda é muito pequeno o espaço dado à participação da sociedade, pois não há procedimentos previamente definidos, tampouco instâncias destacadas para conduzir esses processos participativos, o que inclui até mesmo a fase pós-implantação, quando se coloca a questão da manutenção desses parques.

Um dos principais desafios é de estruturar as diversas fases do processo participativo, a exemplo de experiências internacionais, na qual se prevê um momento inicial de compartiIhamento de informação, avançando para uma participação efetiva nos processos de tomada de decisão, que considere as expectativas e interesses dos atores envolvidos, de modo a fortalecer uma ação colaborativa e pactuada, visando a construção coletiva de conhecimento, fundamental para o compartilhamento das responsabilidades (Petts, 2006; Saenz, 2010; Pahl-Wostl et al., 2007; Jacobi e Franco, 2011).

\section{Conclusões}

A resolução do passivo ambiental associado à degradação das fontes hídricas na cidade de São Paulo, pela sua complexidade, demanda uma nova governança da água. A ênfase tem de se centrar na coordenação das intervenções, o que implica estabelecer novos parâmetros de ação, articulando tanto a dimensão gerencial pautada pela eficiência e efetividade governamentais quanto a visão democrática e participativa. Para tanto, torna-se necessário avançar no fortalecimento de canais de participação e parcerias, que contribuem para a criação de condições de governabilidade e para a garantia de uma governança participativa como referência de redefinição e rearticulação das relações entre Estado e sociedade.

As políticas de recuperação de rios e córregos urbanos e a própria gestão da água urbana inscrevem-se em um contexto em que a política e os instrumentos legais se confrontam com uma lógica de pouca articulação e intersetorialidade da gestão municipal para implantação de respostas efetivas e duradouras. No caso da implantação dos parques lineares na cidade de São Paulo, observam-se as dificuldades de implantar políticas públicas e ações integradas de modo a romper com a lógica na qual prevalece uma visão setorial. 0 modelo de descentralização com transferência do poder para as subprefeituras para atuar de forma intersetorial e mais próxima ao cidadão foi desmontado por gestões entre 2005 e 2012 e não tem se concretizado, reduzindo significativamente sua autonomia administrativa e financeira. Assim, as subprefeituras, que poderiam exercer um papel articulador das diferentes políticas que mantêm interface com a implantação dos parques lineares, particularmente as políticas de habitação, drenagem e saneamento, não avançam nessa direção. A prevalência das políticas setoriais reduz a potencialidade de mudanças em direção a uma nova governança da água na cidade de São Paulo. Isso mostra as dificuldades existentes para implementar políticas que se contrapõem ao paradigma existente, e a complexidade de superar visões tradicionais de gestão, como é o caso das políticas de recuperação de rios e córregos urbanos.

A análise dos processos que relacionam 0 poder político em geral à implantação das mais diferentes políticas públicas explica porque certas políticas e instrumentos legais parecem ser 
mais avançados do que a própria capacidade do poder público para implementá-los, notadamente aqueles relacionados à questão ambiental. As políticas de recuperação de rios e córregos urbanos e a própria gestão da água urbana se inscrevem nesse contexto. A dificuldade de planejar e executar políticas inovadoras no longo prazo não podem prescindir de um agente público que articule as ações e facilite esse diálogo. Esse novo paradigma na gestão dos recursos hídricos na cidade, como é a recuperação de córregos e fundos de vale, abre uma possibilidade de compartilhamento de informação, avançando para uma participação efetiva nos processos de tomada de decisão, que considere as expectativas e interesses dos atores envolvidos, de modo a fortalecer uma ação colaborativa e pactuada, visando à construção coletiva de conhecimento, fundamental para o compartilhamento das responsabilidades.

\section{Pedro Roberto Jacobi}

Universidade de São Paulo, Instituto de Energia e Ambiente, Programa de Pós-Graduação em Ciência Ambiental. São Paulo/SP, Brasil.

prjacobi@gmail.com

\section{Ana Paula Fracalanza}

Universidade de São Paulo, Instituto de Artes, Ciências e Humanidades e Instituto de Energia e Ambiente, Programa de Pós-Graduação em Ciência Ambiental. São Paulo/SP, Brasil.

fracalan@usp.br

\section{Solange Silva-Sánchez}

Universidade de São Paulo, Instituto de Energia e Ambiente, Programa de Pós-Graduação em Ciência Ambiental. São Paulo/SP, Brasil

solss@usp.br

\section{Notas}

(1) Construída sobre o rio Saracura, a Avenida 23 de Maio, implantada sobre o rio Anhangabaú e a Avenida dos Estados, sobre o rio Tamanduateí.

(2) Lei Estadual 1.172/76.

(3) Cf.: http://www.sabesp.com.br/sabesp/filesmng.nsf/D93B6379CD08A597832579CB00043E5C/\$F ile/RelatorioAdministracao.pdf

(4) Os níveis de qualidade das águas para todo o país foram estabelecidos pelo Conselho Nacional do Meio Ambiente - Conama, por meio da Resolução Conama 357/05, relativa às águas superficiais doces, salinas e salobras e da Resolução Conama 396/08, relativa às águas subterrâneas. 
(5) Lei Estadual 9.866/97 (Lei de Proteção aos Mananciais).

(6) Cf.:http://www.ibge.gov.br/cidades

(7) Cf. :http://infocidade.prefeitura.sp.gov.br

(8) Lei no 15.950, de 30 de dezembro de 2013.

(9) http://www.projetotiete.com.br/

(10) Pesquisa realizada pela prefeitura do município de São Paulo, com mais de 25 mil questionários aplicados, dos quais $54 \%$ por meios eletrônicos, visando subsidiar a elaboração do chamado Plano SP 2040.

(11) Lei Municipal 16.050 de 31 de julho de 2014.

(12) Lei no. 16.050/2014.

(13) O Programa Mananciais articula recursos dos governos federal, estadual e de alguns municípios da RMSP, entre os quais o município de São Paulo e conta com recursos do BIRD. Concentra-se na urbanização e saneamento de moradias e loteamentos irregulares instalados nas áreas de mananciais, em particular da região das represas Billings e Guarapiranga.

(140 Relativo à Demanda Bioquímica de Oxigênio (que corresponde à quantidade de oxigênio necessária para ocorrer a oxidação da matéria orgânica biodegradável sob condições aeróbicas).

(15) Lei municipal 14.934/2009.

(16) Em 20 de agosto de 2014, a Câmara Municipal de São Paulo instaurou uma Comissão Parlamentar de Inquérito - CPI com o objetivo de investigar o contrato de concessão firmado entre Prefeitura e Sabesp em 2010.

(17) Comunicação pessoal Gilmar Massone, Coordenador técnico do programa de despoluição de córregos no Município de São Paulo - Programa Córrego Limpo, em 3/9/2014.

(18) OESP, 17 de setembro de 2012, Poluição volta a córregos recuperados, p. C 34.

(19) Lei Municipal 16.050 de 31 de julho de 2014.

\section{Referências}

ALVES, H. P. F. e TORRES, H. G. (2006). Vulnerabilidade socioambiental na cidade de São Paulo: uma análise de famílias e domicílios em situação de pobreza e risco ambiental. São Paulo em Perspectiva. São Paulo, v. 20, n. 1, pp. 44-60.

ARAÚJO, M. F. I. (1992). “Os cem últimos anos na história da cidade e a formação da grande São Paulo”. In: SÃO PAULO (Estado). Secretaria de Planejamento e Gestão. Fundação Seade. Cenários da urbanização paulista: a região administrativa da Grande São Paulo. São Paulo, Fundação Seade, pp. 15-51.

BALTRUSIS, N. e ANCONA, A. L. (2006). Recuperação Ambiental e Saúde Pública. O programa Guarapiranga. Saúde e Sociedade. São Paulo, v. 15, n. 1. 
BARTALINI, V. (2006). A trama capilar das águas na visão cotidiana da paisagem. Revista USP. São Paulo, n. 70, pp. 88-97.

BEYRUTH, Z. (2006). Aprendendo sobre qualidade de vida com as águas poluídas da cidade de São Paulo. Revista USP. São Paulo, n. 70, pp. 46-63.

BROCANELI, P. F. e STUERNER, M. M. (2008). Renaturalização de rios e córregos no município de São Paulo. Exacta. São Paulo, v. 6, n. 1, pp. 147-156.

CASTRO, J. E. (2007). Water governance in the twentieth-first century. Ambient. soc. Campinas, v. 10, n. 2 .

JACOBI, P. R. (1989). Movimentos Sociais e Políticas Públicas. São Paulo, Cortez.

(2011). “Aprendizagem social e governança da água". In: JACOBI, P. (coord.). Aprendizagem social. In: JACOBI, P. R. (coord.). Diálogos e ferramentas participativas: aprender juntos para cuidar da água. São Paulo, IEE/Procam.

(2012). "Governança ambiental, participação social e educação para a sustentabilidade". In: PHILIPPI, A. et al. (eds.). Gestão da natureza pública e sustentabilidade. São Paulo, Manole.

JACOBI, P. R. e FRANCO, M. I. G. C. (2011). "Sustentabilidade, participação, aprendizagem social”. In: JACOBI, P.R. (coord.). Aprendizagem social. In: JACOBI, P.R. (coord.). Diálogos e ferramentas participativas: aprender juntos para cuidar da água. São Paulo, IEE/Procam.

JACOBI, P. R. e GIORGETTI, C. (2009). “Os moradores e a água na bacia do rio Pirajuçara na Região Metropolitana de São Paulo: percepções e atitudes num contexto crítico de degradação de fonte hídricas". In: JACOBI, P. R. (org.). Atores e processos na governança da água no Estado de São Paulo. São Paulo, Annablume.

KIBEL, P. S. (org.) (2007). Rivertown. Rethinging urban rivers. Cambridge/Massachusetts, The MIT Press.

MARQUES, E. e REQUENA. C. (2013). O centro voltou a crescer? Trajetória demográficas diversas e heterogeneidade na São Paulo dos anos 2000. Novos Estudos Cebrap. São Paulo, v. 95, pp. 17-37.

MARTINS, M. L. R. (2011). São Paulo, centro e periferia: a retórica ambiental e os limites da política urbana. Estudos Avançados. São Paulo, v. 25, n. 71.

MMA-Ministério do Meio Ambiente (2006). Secretaria de Recursos Hídricos. Plano Nacional de Recursos Hídricos. Diretrizes, v. 3, Ministério do Meio Ambiente, Secretaria de Recursos Hídricos. Brasília, MMA, 4 v.

MOSTERT, E. et al. (2007). Social learning in European river-basin management: barriers and fostering mechanisms from 10 river basins. Ecology and Society, v. 12, n. 1, p. 19.

NAKAMURA, K. e TOCKNER, K. (2004). River and Wetland Restoration in Japan.3rd European Conference on River Restoration. Zagreb, Croácia. Disponível em: http://www.pwri.go.jp/eng/activity/pdf/ reports/nakamura-tockner040517.pdf. Acesso em: 8 jun 2014.

NÓBREGA, M. (1981). História do Rio Tietê. Belo Horizonte/São Paulo, Itatiaia/Edusp. (Trabalho original publicado em 1948).

PAHL-WOSTL, C. M. et al. (2007). Social learning and water resources management. Ecology and Society. Wolfville, Canadá, v. 12, n. 2, p. 5. 
PETTS, J. (2006). Managing public engagement to optimize learning: reflections from urban river restoration. Human Ecology Review. Canberra, Australia, v. 13, n. 2, pp.172-181.

(2007). Learning about learning: lessons from public engagement and deliberation on urban river restoration. The Geographical Journal. Wales, v. 173, n. 4, pp. 300-311.

RARES, C. S. e BRANDIMARTE, A. L. (2014). O desafio da conservação de ambientes aquáticos e manutenção de serviços ambientais em áreas verdes urbanas: o caso do Parque Estadual da Cantareira. Ambient. soc. [online], v.17, n. 2 [cited 2014-12-07], pp. 111-128. Disponível em: http://www.scielo.br/scielo.php?script=sci_arttext\&pid=S1414-753X2014000200008\&lng=en\& $\mathrm{nrm}=$ iso

REYNOSO, A. E. G. et al. (2010). Rescate de ríos urbanos. Propuestas conceptuales y metodológicas para la restauración y rehabilitaciónde ríos. Universidad Nacional Autonóma de México. Coordinación de Humanidades. Programa Universitario de Estudios sobre la Ciudad. México.

RHOADS, B. L.; WILSON, D.; URBAN, M. e HERRICKS, E. E. (1999). Interaction between scientists and nonscientists in community-based watershed management: emergence of the concept of stream naturalization. Environmental Management. Berlin, v. 24, n. 3, pp. 297-308.

RODRIGUES, M. A. (2009). Avaliação dos benefícios da reabilitação de rios: potencial para aplicação da transferência de benefícios. Dissertação de Mestrado. Lisboa, Universidade Nova de Lisboa.

ROLNIK, R. e KLINK, J. (2011). Crescimento econômico e desenvolvimento urbano: por que nossas cidades continuam tão precárias? Novos estudos - Cebrap. São Paulo, n. 89.

ROLNIK, R. e NAKANO, K. (2000). "Cidade e políticas urbanas no Brasil: velhas questões e novos desafios". In: RATTNER, H. (org.). Brasil no limiar do século XXI: alternativas para a construção de uma cidade sustentável. São Paulo, Edusp.

RUTKOWSKI, E. W.; JACOBI, P. R.; SOUZA, R. M. G. e TAGNIN, R. (2010). “As águas metropolitanizadas do Alto Tietê". In: SALDIVA, P. (org.). Meio ambiente e saúde: o desafio das metrópoles. São Paulo, Ex-Libris Comunicação Integrada.

RUTKOWSKI, E. W. e DE OLIVEIRA, E. G. (1999). “A gestão das águas paulistanas”. In: RUTKOWSKI, E. Bacia Hidrográfica e Bacia Ambiental. São Paulo, Sabesp.

SABESP - Companhia de Saneamento Básico do Estado de São Paulo (2012). A universalização do saneamento no Estado de São Paulo. Governo do Estado de São Paulo, Sabesp.

(2013). Relatório de Sustentabilidade 2013.

SAENZ, I. Z. (2010). "Algunos princípios em elrescate de ríos urbanos". In: Rescate de ríos urbanos. Propuestas conceptuales y metodológicas para la restauración y rehabilitaciónde ríos. Mexico, Universidad Nacional Autonóma de México. Coordinación de Humanidades. Programa Universitario de Estudios sobre la Ciudad.

SÃO PAULO (Município) (2004a). Secretaria Municipal do Verde e do Meio Ambiente-SVMA. Atlas Ambiental do Município de São Paulo - O verde, o território o ser humano: Diagnóstico e bases para definição de políticas públicas para as áreas verdes do município de São Paulo. Coordenação Patrícia Marra Sepe e HarmiTakiya, SVMA, 257 pp.

(2004b). Plano Diretor Estratégico do Município de São Paulo: 2002-2012. São Paulo, Senac, Prefeitura Municipal. 
SÃO PAULO (Município) (2008). Indicadores ambientais e gestão urbana: desafios para a construção da sustentabilidade na cidade de São Paulo / Patrícia Marra Sepe, Sandra Gomes. São Paulo, Secretaria Municipal do Verde e do Meio Ambiente/Centro de Estudos da Metrópole.

(2012). Secretaria Municipal de Desenvolvimento Urbano. Manual de drenagem e manejo de águas pluviais: gerenciamento do sistema de drenagem urbana. São Paulo, SMDU.

(2014). Plano Diretor Estratégico do Município de São Paulo: 2014-2024. São Paulo, Prefeitura Municipal.

SILVA-SÁNCHEZ, S. (2011). Requalificação de córregos urbanos, participação pública e aprendizado social: um estudo de caso no município de São Paulo. In: 3ำ ENCONTRO INTERNACIONAL DA GOVERNANÇA DA ÁGUA. DESAFIOS INTERDISCIPLINARES. Anais. São Paulo, USP/ PROCAMIEA.

(2014). Implementation of riverside parks in the city of São Paulo - progress and constraints. Local Environment: The International Journal of Justice and Sustainability. Disponível em: http:// dx.doi.org/10.1080/13549839.2014.922060

SILVA-SÁNCHEZ, S. e JACOBI, P. R. (2012). Políticas de recuperação de rios urbanos na cidade de São Paulo: possibilidades e desafios. Revista Brasileira de Estudos Urbanos e Regionais. Rio de Janeiro, n. 14.2, pp. 145-161.

(2014). Implementation of riverside parks in the city of São Paulo - progress and constraints. Local Environment: The International Journal of Justice and Sustainability. Disponível em: http:// dx.doi.org/10.1080/13549839.2014.922060

SILVA-SÁNCHEZ, S. e MANETTI, C. (2007). Experiência de reconversão urbana e ambiental da bacia do córrego Água Podre. Parque Linear Água Podre. In: SEMINÁRIO NACIONAL SOBRE O TRATAMENTO DE ÁREAS DE PRESERVAÇÃO PERMANENTE EM MEIO URBANO E RESTRIÇÕES AMBIENTAIS AO PARCELAMENTO DO SOLO-APPURBANA. Anais. São Paulo.

SOLANES, M. e JOURALEV, A. (2006). Water governance for development and sustainability. Serie Recursos Naturales e Infraestrutura. Santiago, Comisión Económica para América Latina y el Caribe (Cepal).

TRAVASSOS, L. R. F. C. (2010). Revelando rios. Novos paradigmas para a intervenção em fundos de vale na cidade de São Paulo. Tese de Doutorado. São Paulo, Universidade de São Paulo.

WATHELY, M. e CUNHA, P. M. (2006). Guarapiranga 2005: como e por que São Paulo está perdendo este manancial: resultados do diagnóstico socioambiental participativo da bacia hidrográfica da Guarapiranga. São Paulo, Instituto Socioambiental.

WORLD BANK (2007). Project performance assessment report Brazil water quality and pollution control project. World Bank. Disponível em: http://www-wds.worldbank.org/external/ default/WDSContentServer/WDSP/IB/2007/10/10/000020953_20071010094544/Rendered/ PDF/396890BR.pdf 
